\section{Human Biology and Legalised Sterilisation}

THE Report of the Departmental Committee on Sterilisation, which was appointed in 1932 to examine and report on the information available regarding the hereditary transmission and other causes of mental disorder and deficiency, to consider the value of sterilisation as a preventive measure, and to suggest what further inquiries might usefully be undertaken in this connexion, was issued on January 18. The Report is a most valuable summary of modern knowledge relating to an urgent social problem. It surveys the causes and extent of mental disabilities, considers the results of sterilisation, and makes important recommendations for a change in the law and practice in Great Britain. A survey of Dominion and foreign legislation relating to sterilisation is included, so that the Committee's own recom. mendations can be considered in the light of practice in other parts of the world.

The Committee recommends that voluntary sterilisation should be legalised in the case of a person who is mentally defective or who has suffered from mental disorder; a person who suffers from, or is believed to be a carrier of, a grave physical disability which has been shown to be transmissible; and a person who is believed to be likely to transmit mental disorder or defect. The Committee was, of course, mainly concerned with the question of sterilisation. The constitution of the Committee was such as to make it possible for the Report to include the statement that "we may perhaps be allowed to say that our recommendations are not a compromise between conflicting views adopted reluctantly in order to secure the appearance of agreement. On the contrary, we were fortunate at the end of a long enquiry in finding ourselves in complete harmony". This in itself distinguishes this Report from that recently issued by a Committee of the British Medical Association.

The Report expresses the opinion strongly that sterilisation should be voluntary, and insists on stringent medical and administrative safeguards to prevent hasty operations. It urges that the same procedure should apply for physical defects which are known to be inherited. It emphasises the point of view that sterilisation cannot replace institutional treatment, and that even if voluntary sterilisation were adopted on the largest scale, there would still be need for more and not less institutional accommodation than is at present available. Finally, the Report stresses the need for further research in several fields. It points out the striking fact that almost all State-aided research in heredity has been inspired by agricultural needs, and asks whether human heredity is not as important as that of cattle and wheat.

From the volume of adverse criticism even now appearing in the popular Press, it is to be assumed that the Committee's recommendations will meet with great opposition in Parliament and that in all probability they will not gain the support of law. It is improbable that any political party will incorporate these recommendations in its own programme, though this may happen perhaps in ten or twenty years' time. In the meantime, it must be sufficient to rejoice in the fact that it is now becoming officially recognised that man is in charge of his own destiny and that no kind of absolute authority will prevent us from tackling our own problems. The Report possesses a unique interest, for it represents the first attempt in Great Britain to apply pure biology in social practice. It is a scientific document, and its recommendations are in no way coloured by religious or political considerations. It heralds a new era in social legislation.

\section{A Panorama of Geometry}

Principles of Geometry. By Prof. H. F. Baker. Vol. 5: Analytical Principles of the Theory of Curves. Pp. $\mathrm{x}+247$. (Cambridge: At the University Press, 1933.) 15s. net.

T $\mathbf{T}$ will be immediately admitted by all mathe1 maticians that the foundations of pure geometry were well and truly laid by the Greeks in the period preceding and succeeding the time of Christ. They investigated in great detail the properties of the straight line, the circle and the conic sections. They had few general principles governing their researches ; they were on the outlook for interesting geometrical properties wherever they could find them. On the other hand, Euclid attempted to collect all these scattered theorems and to present them in a coherent whole, studying at the same time so far as he could the underlying postulates and axioms. Nevertheless, it still remains true that the discovery of individual theorems was rather at haphazard.

It fell to Descartes (1596-1650) to devise the geometrical representation of an equation in $x$ and $y$ by means of abscissæ and ordinates. Thus was introduced a general method of attacking any 